"...there will be no more elections

to the GDC, we no longer have a vote,

or a voice or any influence at all.

It's over."

\title{
A profession no longer
}

Various activities and circumstances have conspired in recent times to bring us to the recent publication of the Government's White Paper on the regulation of health professionals. ${ }^{1}$ This is a result of various pressures, not least of which is the Shipman case. The full document includes this apparently reassuring sentence: 'The professional regulators will be independent of Government and led by an equal partnership of independently appointed professionals and members of the pubic.'

In a Press Statement, the General Dental Council (GDC) welcomed the Government's clear indication about the future and said it would need to consider the proposals [my italics] in more detail. GDC President Hew Matheson, a dentist but possibly the last ever dentist to hold that office, is quoted as saying: 'The current Council is due to step down in 2008 so one of our immediate priorities is to make sure there is a smooth transition to a new fully appointed Council.' I may be wrong but to me there is no suggestion there whatever that this is a 'proposal', rather that it is a done deal. In short there is no proposal in this White Paper, there is only notice of implementation. Just as last year's NHS dental contract was imposed, so too will this thinly disguised but cleverly insinuated device in the name of better governance.

But, what does 'step down' mean in real language? It means disbanded, got rid of, dumped. Let us be absolutely clear, there will be no more elections to the GDC, we no longer have a vote, or a voice or any influence at all. It's over. In future our annual retention fee is just that, a sum of money to allow us the apparent privilege to carry out our work in our field. It is a licence to earn a living in a particular activity and nothing else. The sum of the fee can be raised and the funds spent without any reference at all to those of us who pay it and without our having any say in the matter whatsoever, since we will no longer have any representation.

The action is tantamount to the Government announcing that it has decided that the present set of Members of Parliament will 'step down' in 2008 and be replaced by an appointed House of Commons. The implication is that the MPs the electorate chose are not always the mix that is desirable for governance and that someone has deemed it necessary to intervene as they better understand what is required. The poll tax riots of the late 1980s would look like a village fete in comparison.

In the euphemistic language in which these things are couched, the BDA has responded with concern that 'the profession's confidence in the system will be undermined'. This goes directly to the heart of the matter. The essence of a profession is self governance: a body of men and women who can act responsibly and be self-governing. That is the deal society offers and which we have upheld. It is the exchange over which we will no longer have any control but by which we will be measured, judged and possibly even have our livelihoods removed. The pendulum has swung too far.

The GDC has moved in recent years to be pragmatic, walking a difficult line between kowtowing to Government and taking the reasonable route to protection of the public. In many ways it should be congratulated for having been far more effective and efficient than its original parent the GMC. However, the profession as a whole has been responsible for many of the innovations and willing implementations of the improvements that now safeguard dental patients and simultaneously enhance the work and life of members of the dental profession; the scheme to aid and recover dentists suffering from substance abuse, the VDP scheme, implementing continuing professional development, pushing for the private patients' complaint service and many more. The key word is 'responsible'. We have been responsible and we have shown ourselves worthy of the trust placed in us by society, but are now to be penalised for it.

It is not just we dentists who are affected by this. The Establishment is about to effectively also disenfranchise and indeed de-professionalise the entire set of team members that it has been at such pains to so elaborately bring into the dental fold. How duped should Dental Care Professionals now feel? At what should be the triumphal moment of their long struggle to be recognised as professionals they are having that accolade cruelly torn from their uniforms and thrown in the dust. DCP? No, DCO - Dental Care Operative. Except they, like us, will still have to pay the retention fee. Perhaps that should now be labelled as another of the stealth taxes - the Licence to Work Tax.

Amid much publicity, the GDC last year celebrated its $50^{\text {th }}$ Anniversary. Sir Wilfred Fish, knighted for his part in creating an independent, self-governing dental profession in 1956 with an existence apart from the medical profession, must be turning in his grave. The Dental Profession 1956-2007 R.I.P, with adjoining spaces in the cemetery for the Medical Profession and others.

1. Trust, Assurance and Safety - The Regulation of Health Professionals in the 21st Century. www.dh.gov.uk

Stephen Hancocks OBE Editor-in-Chief DOI: $10.1038 /$ bdj.2007.197 